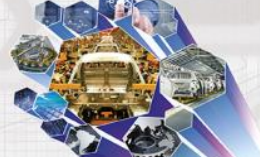

\title{
CONTROLE ANTECIPATÓRIO PARA OTIMIZAÇÃO DO USO DE OXIGÊNIO PARA ENRIQUECIMENTO DO AR DE COMBUSTÃO DO FORNO WB2 DA LAMINAÇÃO DE TIRAS A QUENTE DA APERAM*
}

\author{
Pedro Henrique Barbosa Souza ${ }^{1}$ \\ José Maria Miranda Madureira² \\ Paulo Vicente Correa ${ }^{3}$ \\ Marcos Antônio Araújo 4 \\ Gláucio Barros Barcelos 5 \\ Felipe Grativol Lima
}

\section{Resumo}

A Aperam é uma grande consumidora de gases do ar, principalmente Argônio. A produção de Argônio é feita através de coluna de destilação, onde são também extraídos Oxigênio e Nitrogênio. A modalidade de contrato adotada pela Aperam é do tipo take-or-pay para todos os gases, porém nem todo Oxigênio produzido era consumido. A Aperam então desenvolveu um projeto visando aproveitar esta "sobra" de Oxigênio no seu forno Walking Beam, para enriquecimento do ar de combustão. A utilização de Oxigênio permite reduzir, de maneira indireta, o consumo de Gás Natural neste forno. Após a implantação do projeto a Aperam está apta a consumir acima da capacidade de Oxigênio produzida, sendo necessário implementar uma estratégia de controle que permita limitar a máxima velocidade deste gás na tubulação (risco de explosões) e reduzir a interferência entre os diversos consumidores, o que poderia provocar desarmes ou oscilações na estequiometria dos gases. Para isto foi aplicado técnicas de controle antecipatório. Este trabalho irá abordar as estratégias de controle utilizadas, sua sintonia e os resultados obtidos.

Palavras-chave: Controle antecipatório; Otimização.

\section{FEEDFORWARD CONTROL APPLIED TO OPTIMIZE THE OXYGEN USED TO ENRICHMENT OF COMBUSTION AIR IN THE FURNACE WB2 OF HOT STRIP MILL IN APERAM}

\section{Abstract}

Aperam is a large consumer of air gases, mainly argon. The production of argon is made through a distillation column, where oxygen and nitrogen are also extracted. The contract modality adopted by Aperam is the take-or-pay for all gases, but not all oxygen produced was consumed. Aperam then developed a project to use this oxygen available in your Walking Beam furnace for enrichment of combustion air. The use of oxygen reduces, indirectly, the consumption of natural gas in this furnace. After the project implementation, Aperam is able to consume over capacity of oxygen produced, being necessary to implement a control strategy designed to limit the maximum speed of this gas in the pipe (risk of explosion) and reduce interference between different consumers, which could cause trips or oscillations in stoichiometry of gases. For this feedforward control techniques was applied. This paper will show the control strategies used, their tuning and the results obtained.

Keywords: Feedforward Control; Optimization.

1 Analista de Automação, Gerência de Automação, Instrumentação e TI Industrial, Aperam, Timóteo, Minas Gerais.

2 Engenharia Eletrônica, Diretor, L\&M Engenharia, Belo Horizonte, MG.

3 Engenharia Eletrônica, Diretor, L\&M Engenharia, Belo Horizonte, MG.

4 Engenheiro de Projetos, Gerência de Engenharia, Aperam, Timóteo, Minas Gerais.

5 Analista de Automação, Gerência de Automação, Instrumentação e TI Industrial, Aperam, Timóteo, Minas Gerais.

6 Analista de Automação, Gerência de Automação, Instrumentação e TI Industrial, Aperam, Timóteo, Minas Gerais.

* Contribuição técnica ao $18^{\circ}$ Seminário de Automação e TI Industrial, 23 a 26 de setembro de 2014, São Paulo, SP, Brasil. 


\section{INTRODUÇÃO}

A Aperam é uma grande consumidora de gases do ar, principalmente o Argônio. Estes gases são adquiridos de uma empresa especializada que os obtêm por coluna de destilação. A modalidade de contrato entre as partes é do tipo take-or-pay. Visando aproveitar o volume disponível de oxigênio contratado, a Aperam desenvolveu um projeto para enriquecer o ar de combustão do seu maior consumidor de gás natural da planta de Timóteo-MG, o Forno Walking Beam, WB2, situado na linha de laminação de tiras a quente.

Com a implantação deste projeto houve a necessidade de reduzir a possibilidade de interferências nos equipamentos consumidores de oxigênio da empresa, pois após implantação deste sistema é possível demandar mais oxigênio que a quantidade ofertada. Isto foi definido a fim de otimizar o uso de oxigênio na planta, objetivando consumir na maioria do tempo $100 \%$ do oxigênio disponível. Assim, quando um consumidor reduzir a sua demanda, o outro estará disponível para consumir o volume restante.

No ramo da linha de distribuição de oxigênio onde este projeto foi instalado, existia somente um consumidor, Fornos de Recozimento da Linha de Recozimento e Decapagem de Bobinas, RB1, da Laminação a Frio de Aços Inoxidáveis. Com isso, este seria o equipamento com maior probabilidade de sofrer interferências devido ao novo consumidor de oxigênio.

A estratégia de controle a ser adotada deve contemplar as diversas possibilidades de interferência que estes consumidores poderiam ter entre si, além de garantir a segurança da linha eliminando o risco de explosão devido a alta velocidade de oxigênio no ramo principal.

\section{DESCRIÇÃO DO PROCESSO}

\subsection{Laminação de Tiras a Quente}

O processo de Laminação de Tiras a Quente (LTQ), representado na Figura 1, tem como objetivo principal transformar placas de aços Inoxidáveis, Siliciosos e Carbono, produzidas na aciaria em bobinas ou chapas grossas. Primeiramente as placas passam por um processo de reaquecimento no Forno Walking Beam até uma temperatura ideal para a laminação.

A placa, com espessura em torno de $200 \mathrm{~mm}$, passa pelo laminador desbastador (Rougher), tendo sua espessura reduzida a valores que podem variar de $250 \mathrm{~mm}$ até $14 \mathrm{~mm}$. A chapa intermediária, proveniente da laminação de desbaste, será reduzida a uma espessura final objetivada que pode variar entre $12 \mathrm{~mm}$ e $2 \mathrm{~mm}$ durante 0 processo de laminação de acabamento (Steckel). Após a laminação de acabamento, a tira é resfriada até uma temperatura objetivada pela ação de jatos d'água na zona de resfriamento e em seguida é realizado o bobinamento da tira laminada.

\footnotetext{
* Contribuição técnica ao $18^{\circ}$ Seminário de Automação e TI Industrial, 23 a 26 de setembro de 2014, São Paulo, SP, Brasil.
} 

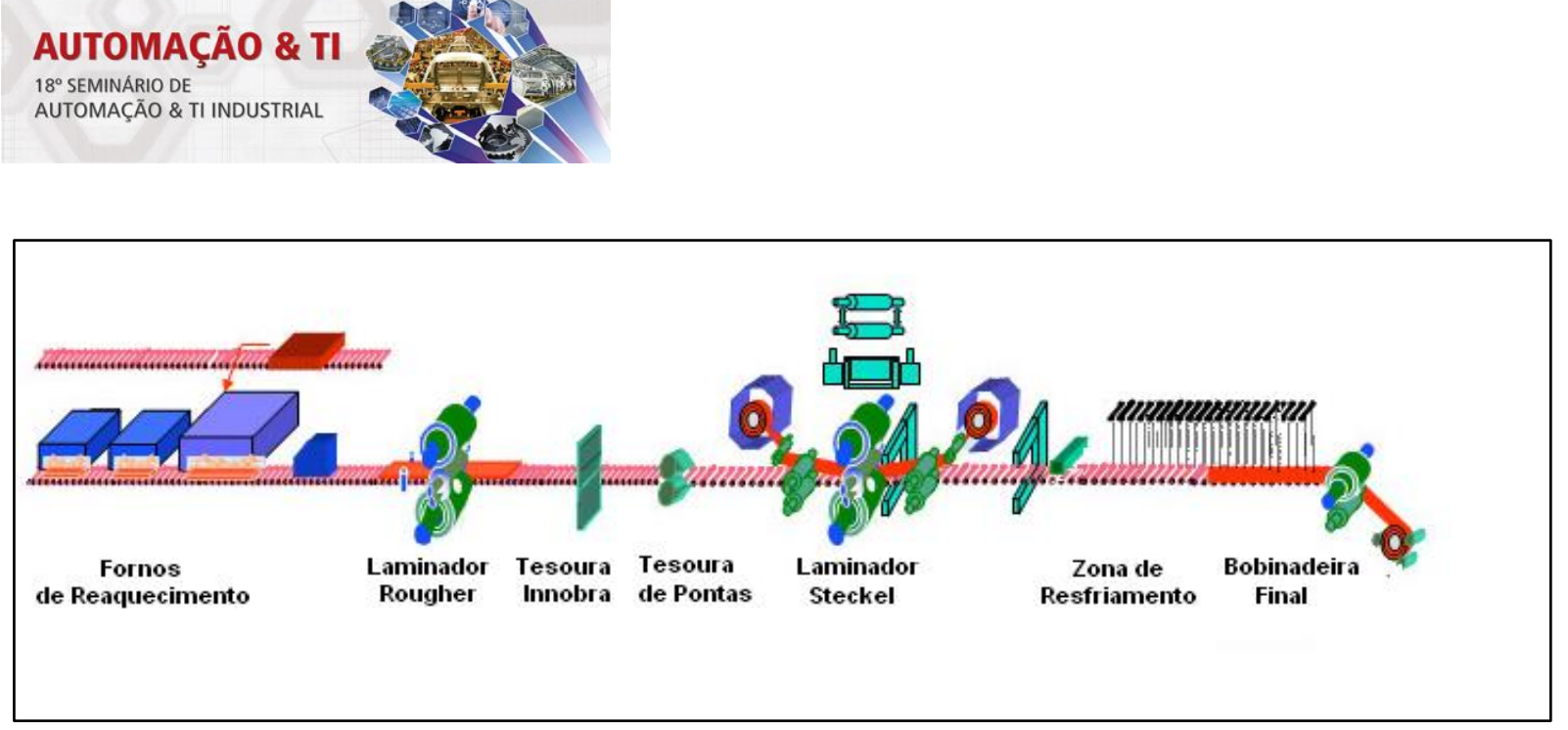

Figura 1: Processo produtivo da Laminação de Tiras a Quente.

\subsection{Forno de Reaquecimento de Placas Walking Beam}

O forno de reaquecimento de placas de soleiras caminhantes, Walking Beam-WB2, tem a função de aquecer as placas provenientes da aciaria até a temperatura ideal de laminação de cada tipo de aço. Este forno é dividido em 8 zonas de controle de temperatura, totalizando uma potência térmica instalada de aproximadamente $74 \mathrm{MW}$ e utiliza como combustíveis o Gás de Alto Forno, GAF, proveniente do processo produtivo de gusa nos Altos Fornos e Gás Natural, GN, um dos insumos de maior valor nos custos totais de produção.

Para redução das perdas energéticas, este forno possui um recuperador de calor, cuja função é aquecer o ar de combustão através da troca térmica com os fumos gerados na combustão.

Para melhorar a eficiência energética deste forno foi implantada uma estação de enriquecimento do ar de combustão com oxigênio, cuja função é diminuir a demanda de energia para uma mesma condição de consumo, reduzindo assim o consumo de Gás Natural e se beneficiando da disponibilidade de Gás de Alto Forno.

\section{DESENVOLVIMENTO}

Com o enriquecimento do ar de combustão com oxigênio há aumento da potência aplicada ao forno, pois com um mesmo volume total de ar é capaz de queimar uma quantidade maior de combustível por unidade de tempo, além de proporcionar elevação da temperatura de chama e redução do volume de fumos gerados para uma mesma potência. Essa melhoria de eficiência diminui a demanda de energia do forno para uma mesma condição de consumo.

A combinação de um controlador em malha fechada com um controle antecipatório pode melhorar significativamente o desempenho de um simples controlador sempre que existir um distúrbio que pode ser medido antes dele afetar a saída do processo. Idealmente, um controle antecipatório pode eliminar completamente o efeito do distúrbio medido na saída do processo. Mesmo quando existir erro de modelagem, o controle antecipatório pode geralmente reduzir os efeitos do distúrbio de forma mais eficaz que o controlador em malha fechada sozinho. [1]

Segundo Seborg et al. [1], os benefícios econômicos do controle antecipatório podem ser baixo custo de operação e/ou aumento da capacidade de venda do produto devido à sua qualidade mais consistente.

O controle antecipatório é sempre usado com um controle em malha fechada, pois neste sistema de controle é esperado que o sistema alcance sempre o setpoint, ou

\footnotetext{
* Contribuição técnica ao $18^{\circ}$ Seminário de Automação e TI Industrial, 23 a 26 de setembro de 2014, São Paulo, SP, Brasil.
} 
referência, e ainda suprima distúrbios não medidos que sempre estão presentes em qualquer processo real.

O aumento da velocidade do oxigênio devido à demanda maior que a quantidade disponível para consumo pode ser interpretado pela queda da pressão da entrada da estação de redução e controle, pressupondo que isso signifique indisponibilidade de oxigênio. Assim, constatou-se que através de técnicas de controle antecipatório poderia evitar que o sistema demandasse mais oxigênio que o ofertado, além de ocorrências de desarmes da estação e assim otimizar o sistema de enriquecimento de oxigênio no Forno WB2, sem interferir nos Fornos da RB1.

\subsection{Estratégias de Controle}

A limitação de vazão em função da pressão de oxigênio na entrada da estação objetiva reduzi-la quando a pressão estiver baixa, pressupondo que isso signifique indisponibilidade de gás. Uma pressão baixa pode significar uma velocidade excessiva na tubulação quando exigida a máxima vazão. A fim de garantir a segurança do sistema e o uso otimizado do volume de oxigênio disponível sem interferência nos sistemas dos outros consumidores foram desenvolvidas duas estratégias para limitar a vazão da estação de oxigênio (Controle antecipatório por fator constante, Controle antecipatório com fator gerado por PID).

\subsubsection{Controle antecipatório por fator constante}

Como a tubulação da linha de distribuição de oxigênio para esta estação é de aço carbono, a velocidade para efeito de segurança pode ser arbitrada em $20 \mathrm{~m} / \mathrm{s}$. O diâmetro da tubulação a montante é de 3 polegadas, correspondente a uma área de $0,00478 \mathrm{~m}^{2}$. Consequentemente, pode-se calcular a vazão máxima utilizando a pressão na linha e a velocidade máxima, como é demonstrado na Equação 1:

$$
Q_{\max }=V_{\max } \times S \times P \times K
$$

onde $Q_{\max }$ representa a vazão máxima, $V_{\max }$ é a velocidade máxima, $S$ é a área da seção transversal da tubulação, $P$ é o fator de compensação em função da pressão na linha e $K$ é o fator de compensação de temperatura.

Assim de acordo com o valor da pressão de entrada, será definida a vazão máxima da estação, como está demonstrado na Tabela 1, evitando, portanto, a atuação do pressostato de segurança e com isso desarme da estação de O2.

Tabela 1. Pressão versus vazão máxima

\begin{tabular}{|c|c|}
\hline $\begin{array}{c}\text { Pressão de Entrada da } \\
\text { Estação (bar) }\end{array}$ & Vazão Máxima $\left(\mathrm{Nm}^{3} / \mathrm{h}\right)$ \\
\hline 13 & 3100 \\
\hline 12 & 2790 \\
\hline 11 & 2480 \\
\hline 10 & 2170 \\
\hline 9 & 1860 \\
\hline
\end{tabular}

$\mathrm{Na}$ Figura 2, pode-se visualizar o diagrama referente a esta estratégia de controle, onde a demanda de vazão calculada através da Equação 2 utilizando o valor de \%O2 no ar de combustão solicitado pelo operador, é limitada por um valor fixo em função da pressão da entrada.

\footnotetext{
* Contribuição técnica ao $18^{\circ}$ Seminário de Automação e TI Industrial, 23 a 26 de setembro de 2014, São Paulo, SP, Brasil.
} 


$$
Q_{O 2}=\frac{Q_{O 2}+Q_{a c}}{0,79} \times\left(\% O_{2}-0,21\right)
$$

onde $\% \mathrm{O}_{2}$ é o percentual de oxigênio solicitado pelo operador, $\mathrm{Q}_{\mathrm{O} 2}$ é a vazão de oxigênio e $\mathrm{Q}_{\mathrm{ac}}$ é a vazão de ar de combustão.

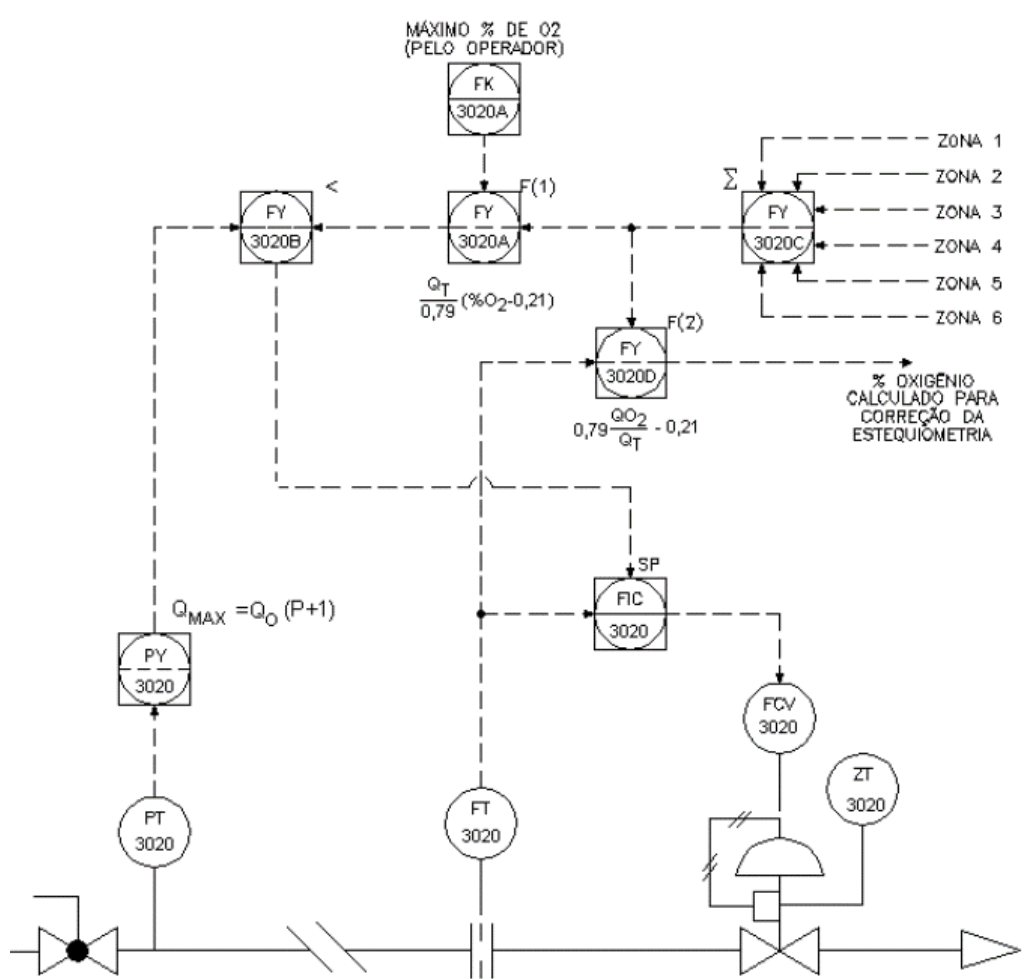

Figura 2. Diagrama da estratégia de controle de vazão de oxigênio do forno WB2 utilizando limitador fixo em função da pressão.

\subsubsection{Controle antecipatório com fator gerado por PID}

Outra estratégia seria introduzir um controlador PID de pressão como fornecedor do limite de vazão, visto que a vazão própria é a principal responsável pela queda da pressão por perda de carga ao longo do caminho, pois através da sintonia da malha deve conseguir a melhor relação custo/benefício e se estabilizar na máxima vazão que a pressão permitir.

Então se utilizou um controlador PID com ação direta para limitar a vazão de oxigênio desta estação de acordo com a pressão da entrada. Deste modo, à medida que a pressão reduza abaixo do valor estipulado, o controlador limita a vazão máxima que pode ser demandada pelo operador.

$\mathrm{Na}$ Figura 3, pode-se visualizar o diagrama referente a esta estratégia de controle, onde a demanda de vazão calculada é limitada pela VM, variável manipulada, do PIC, controlador e indicador de pressão.

* Contribuição técnica ao $18^{\circ}$ Seminário de Automação e TI Industrial, 23 a 26 de setembro de 2014, São Paulo, SP, Brasil. 


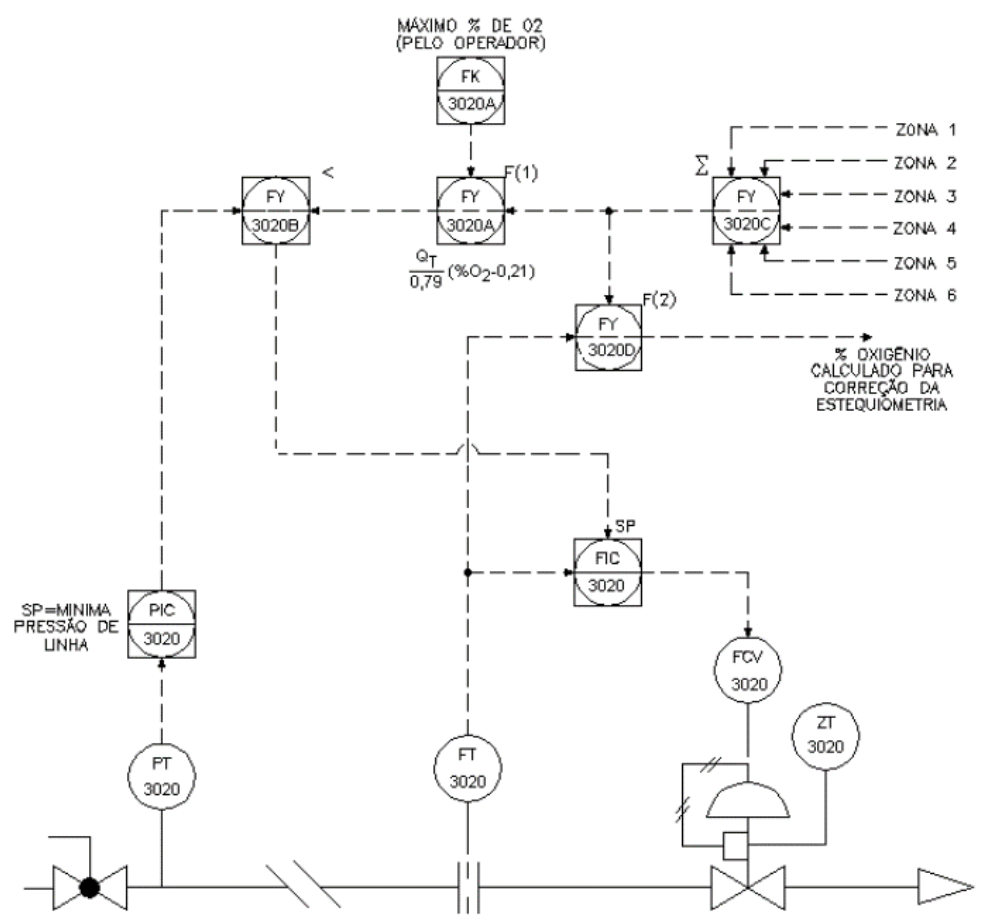

Figura 3. Diagrama da estratégia de controle de vazão de oxigênio do Forno WB2 utilizando controlador PID como limitador da vazão.

\subsection{Análise e Seleção da Estratégia de Controle a ser Implantada}

A estratégia descrita no item 3.1.1 pode levar à oscilação na medida em que o limite de vazão, quando aplicado, altera a pressão e essa reflete no próprio limite, uma referência cruzada em realimentação positiva.

Por este fato, optou-se por utilizar um controlador PID, estratégia descrita no item 3.1.2, por ser gerenciado pela sintonia da malha e assim não gerar distúrbios nos controladores do Forno WB2, pois uma grande variação na vazão de oxigênio reflete uma grande oscilação na relação estequiométrica dos gases envolvidos na combustão, gerando um descontrole de temperatura.

Este controlador exerce uma função antecipatória, por evitar que ocorram demandas maiores do que a quantidade ofertada, além de manter o consumo de oxigênio sempre próximo do valor disponível, não necessitando intervenções operacionais e garantindo que a estação não desarme por baixa pressão e gere distúrbios no forno.

\subsection{Temporização da Informação}

Devido ao atraso de transporte do sistema, representado pelo tempo de transporte do oxigênio até os queimadores do forno, aplicou-se um filtro de primeira ordem sobre o valor de percentual de oxigênio no ar de combustão calculado, pela Equação 3, onde $\% \mathrm{O}_{2}$ é o percentual de oxigênio solicitado pelo operador, $\mathrm{Q}_{02}$ é a vazão de oxigênio e $Q_{\mathrm{ac}}$ é a vazão de ar de combustão:

$$
\% O_{2}=0,79 \frac{Q_{O 2}}{Q_{O 2}+Q_{a c}}+0,21
$$

* Contribuição técnica ao $18^{\circ}$ Seminário de Automação e TI Industrial, 23 a 26 de setembro de 2014, São Paulo, SP, Brasil. 
No domínio da frequência o filtro corresponde a uma função de transferência do seguinte tipo, representado pela Equação 4:

$$
H(s)=\frac{1}{1+\theta s}
$$

onde $\theta$ representa o tempo de atraso.

O objetivo é evitar que variações bruscas ou ruídos na vazão de oxigênio sejam refletidos rapidamente em tempo e amplitude reais nos set-points de vazão de ar e combustível na estratégia de controle de temperatura das zonas do Forno WB2.

$\mathrm{Na}$ figura 4, está representado o fluxograma da estação de oxigênio do forno WB2.

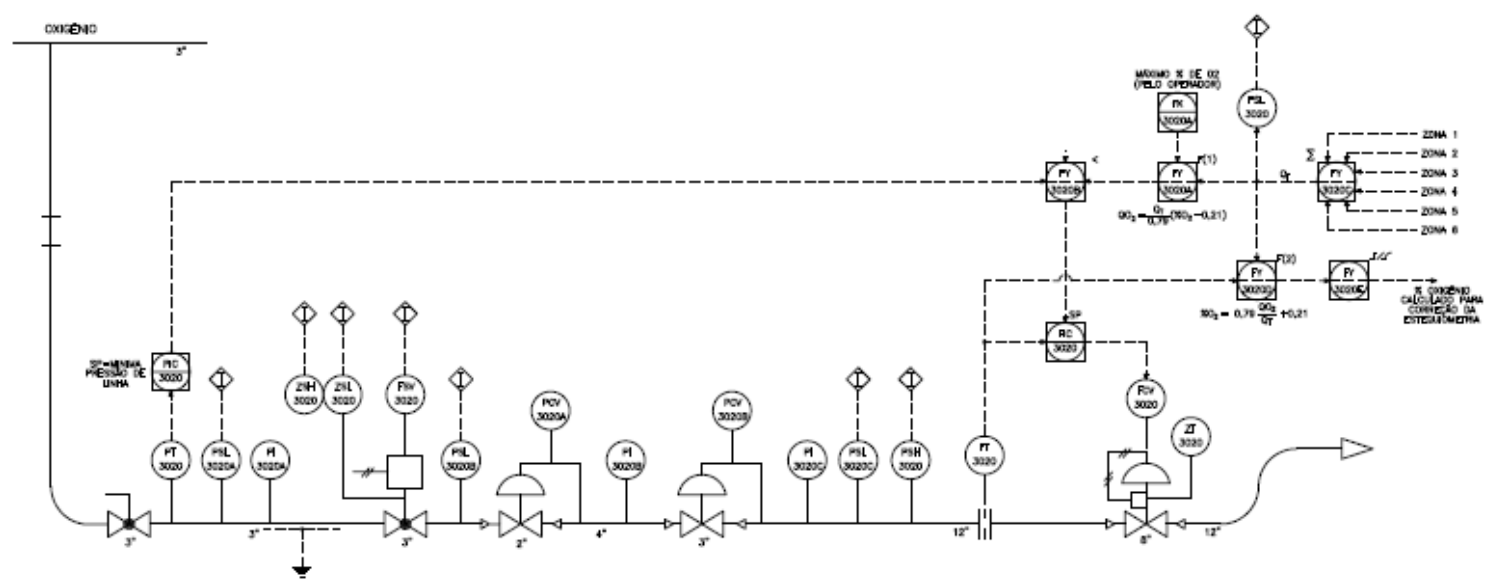

Figura 4. Diagrama P\&I da estação de injeção de oxigênio no ar de combustão do Forno WB2.

\section{RESULTADOS}

Após testes e simulações, foi definido que o valor de pressão mínima de trabalho é de 13 bar, ou seja, abaixo desta pressão o sistema começa a limitar a demanda de vazão de oxigênio, visto que este valor garante tanto a velocidade abaixo do limite de segurança na tubulação de distribuição dos dois consumidores quanto a não interferência nos Fornos da RB1.

A estação de oxigênio do Forno WB2 foi projetada para uma vazão máxima de $3000 \mathrm{Nm}^{3} / \mathrm{h}$, enquanto a vazão máxima da estação dos Fornos da RB1 é de $2000 \mathrm{Nm}^{3} / \mathrm{h}$. De forma que o Forno WB2 só consumirá sua vazão máxima se a demanda dos Fornos da RB1 for baixa, pois a vazão da rede geral é limitada em $3400 \mathrm{Nm}^{3} / \mathrm{h}$.

Na Figura 5 está representado uma análise gráfica realizada no sistema de coleta de informações de processo, PIMS, utilizando o software PI ProcessBook® da OSIsoft, onde a linha azul representa a vazão de oxigênio da estação do Forno WB2, enquanto a linha verde representa a vazão da estação de oxigênio dos fornos da RB1. Já na Figura 6, pode ser visualizado o percentual de oxigênio no ar de combustão requerido pelo operador do Forno WB2 e o valor real de enriquecimento do ar de combustão, no mesmo período da análise da Figura 5.

* Contribuição técnica ao $18^{\circ}$ Seminário de Automação e TI Industrial, 23 a 26 de setembro de 2014, São Paulo, SP, Brasil. 


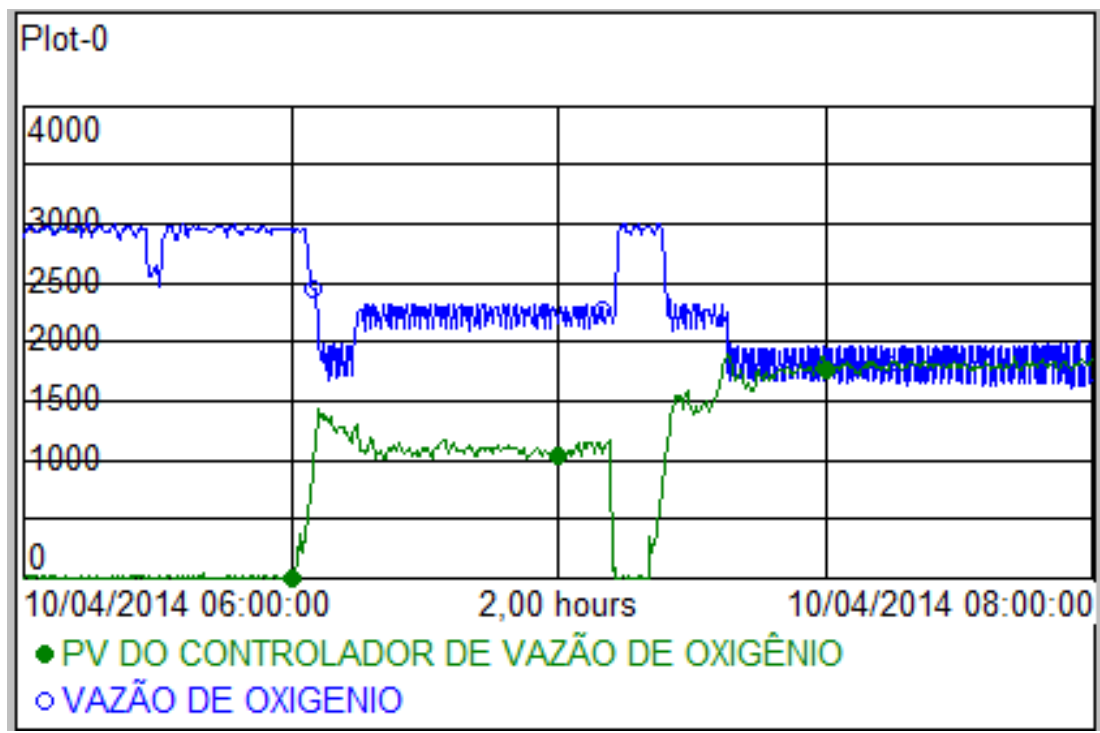

Figura 5. Comparativo entre as vazões das estações de oxigênio dos Fornos WB2 e da RB1.

Analisando a Figura 5, contata-se que no momento em que a RB1 reduz o consumo de oxigênio o controle antecipatório faz com que automaticamente toda a quantidade exigida pelo Forno WB2 seja consumida. E assim que a RB1 volta a demandar oxigênio, o controlador limita a vazão máxima disponível para o WB2, não interferindo portanto no processo da RB1 e permitindo que a quantidade disponível de oxigênio seja consumida.

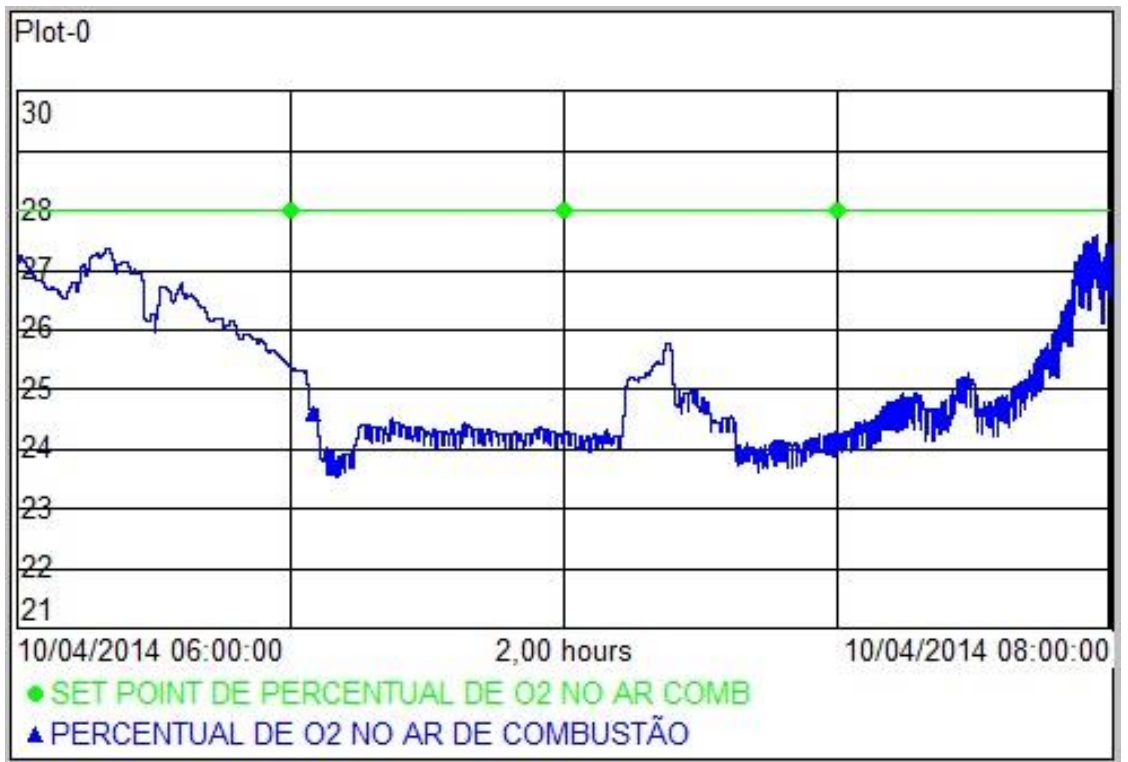

Figura 6. Demanda de percentual de oxigênio no ar de combustão do Forno WB2.

Como pode ser visto na Figura 6, a demanda de percentual de oxigênio no ar de combustão do forno WB2 solicitada pelo operador se manteve em $28 \%$, comprovando, contudo, que a limitação de vazão ocorreu em função da demanda de oxigênio dos Fornos da RB1, sentido pela queda de pressão na entrada da estação. Esta pressão se manteve sempre acima do limite mínimo definido, 13 bar, como é demonstrado na Figura 7 onde a linha azul representa a pressão de oxigênio da estação do forno WB2, enquanto a linha verde representa a pressão da estação de oxigênio dos fornos da RB1. Assim, é garantido que a velocidade do oxigênio não ultrapasse o valor limite de segurança, e o uso da quantidade de oxigênio disponível.

* Contribuição técnica ao $18^{\circ}$ Seminário de Automação e TI Industrial, 23 a 26 de setembro de 2014, São Paulo, SP, Brasil. 


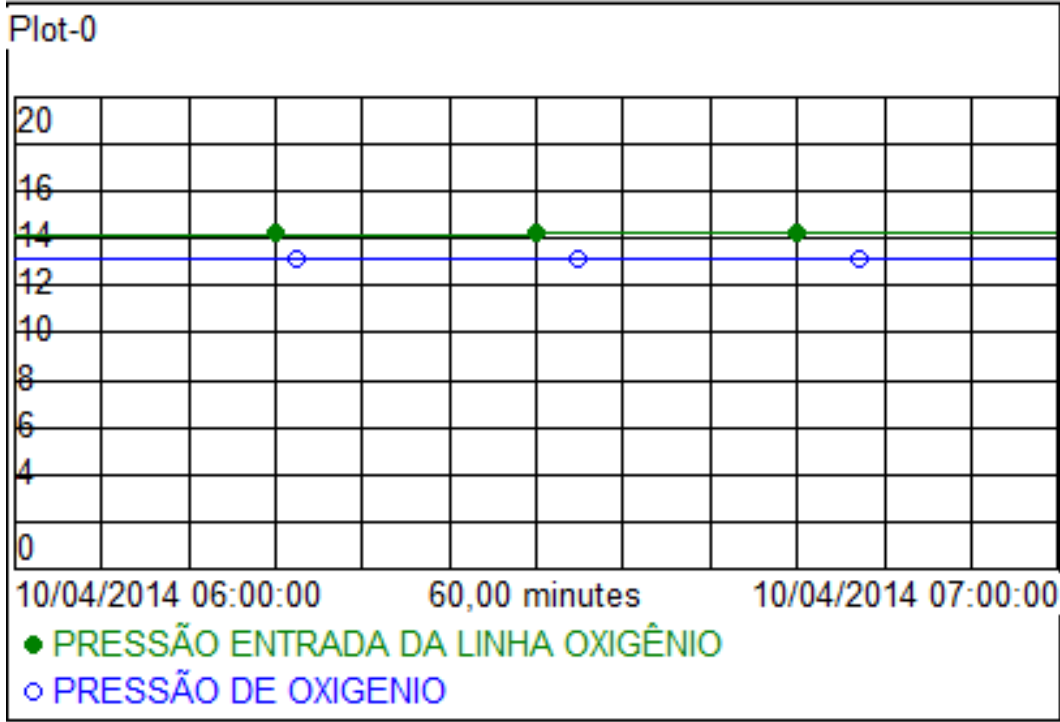

Figura 7. Avaliação do funcionamento do controle antecipatório implantado.

A fim de verificar o benefício da otimização do uso de oxigênio $\left(\mathrm{O}_{2}\right)$ e consequente redução do consumo de gás natural(GN), foi realizado uma análise de funcionamento do sistema de controle antecipatório, quando o forno estava com as mesmas condições de processo, onde durante 30 minutos foi utilizado um volume de aproximadamente $858 \mathrm{~m}^{3}$ de $\mathrm{O}_{2}$ para enriquecimento do ar de combustão e foi totalizado o volume GN consumido. Depois, mais 30 minutos, devido ao aumento do volume de oxigênio disponível, o sistema automaticamente incrementou o consumo de $\mathrm{O}_{2}$, totalizando um volume de $1455 \mathrm{~m}^{3}$, e foi analisado o volume de $\mathrm{GN}$ usado. $\mathrm{O}$ resultado está apresentado na Tabela 2.

Tabela 2. Consumo de gás natural em função do aumento do consumo de oxigênio

\begin{tabular}{|c|c|}
\hline Volume de Oxigênio $\left(\mathrm{m}^{3}\right)$ & Volume de GN $\left(\mathrm{m}^{3}\right)$ \\
\hline 858 & 2765 \\
\hline 1455 & 2564 \\
\hline
\end{tabular}

Através desta análise, cujo resultado está representado na Tabela 2, verifica-se uma redução de $7 \%$ no volume consumido de GN pelo aumento do enriquecimento do ar de combustão com oxigênio.

Sem o sistema de controle antecipatório, para o uso contínuo de oxigênio sem interferir no outro consumidor a necessidade de intervenção operacional seria intensa. Caso a variação no consumo fosse rápida, os sistemas de segurança atuariam, desarmando a estação de controle e gerando distúrbios no forno devido a grande variação na relação estequiométrica dos gases envolvidos no processo de combustão. Esta estratégia de controle foi implantada antes do startup do projeto de enriquecimento do ar de combustão do Forno WB2 com oxigênio, em dezembro de 2013, onde foram realizados os testes e sintonias do controlador.

A vazão máxima disponível para o enriquecimento do ar de combustão do Forno WB2 era de $1500 \mathrm{Nm}^{3} / \mathrm{h}$, sem interferir no sistema dos Fornos da RB1. Como pode ser visto na Tabela 3, com o sistema de controle implantado, as vazões médias mensais de oxigênio no Forno WB2 estão acima da máxima disponível, demonstrando que

* Contribuição técnica ao $18^{\circ}$ Seminário de Automação e TI Industrial, 23 a 26 de setembro de 2014, São Paulo, SP, Brasil. 
sempre que os Fornos da RB1 reduzem a demanda de oxigênio, o sistema está automaticamente consumindo todo o volume disponível.

Tabela 3. Vazão média mensal de oxigênio no Forno WB2 em Nm³/h

\begin{tabular}{|c|c|c|c|c|}
\hline \multicolumn{5}{|c|}{ Vazão Média de Oxigênio em Nm³/h } \\
\hline Janeiro & Fevereiro & Março & Abril & Média \\
\hline 1771 & 1656 & 1900 & 1678 & 1751 \\
\hline
\end{tabular}

$\mathrm{Na}$ Tabela 4 estão demonstrados os consumos médios mensal de GN em 2013 e em 2014 por tipo de aço produzido, onde se pode visualizar uma redução no consumo de GN como objetivado pelo projeto. Um dos fatores de maior contribuição para esta redução é o uso otimizado do oxigênio permitido pelo controlador antecipatório implementado.

Tabela 4. Consumo médio mensal de gás natural em m³/ton por tipo de aço.

\begin{tabular}{|c|c|c|c|c|c|c|}
\hline \multirow{2}{*}{ Tipo de Aço } & \multirow{2}{*}{2013} & \multicolumn{6}{|c|}{2014} \\
\cline { 3 - 7 } & & Janeiro & Fevereiro & Março & Abril & Média \\
\hline $3 X X$ & 37,20 & 34,50 & 34,48 & 33,26 & 33,03 & 33,82 \\
\hline CG & 57,00 & 55,86 & 57,16 & 53,86 & 50,46 & 54,34 \\
\hline $4 X X$ & 33,90 & 30,60 & 30,89 & 32,18 & 31,14 & 31,20 \\
\hline GO & 34,50 & 30,10 & 34,38 & 32,44 & 32,56 & 32,37 \\
\hline GNO & 25,80 & 24,90 & 26,30 & 26,00 & 27,49 & 26,17 \\
\hline Carbono & 36,28 & 33,84 & 29,60 & 36,86 & 33,68 & 33,50 \\
\hline
\end{tabular}

É importante ressaltar que nesta análise de consumo apresentado na Tabela 3 foram desconsideradas as paradas emergenciais e programadas.

\section{CONCLUSÃO}

A utilização do controlador PID como gerador do limite de vazão de oxigênio possibilitou o ajuste do tempo de resposta do sistema de limitação de vazão, através da sintonia dos parâmetros de controle e assim conseguiu-se reduzir os efeitos oscilatórios devido a correlação entre as variáveis pressão e vazão de oxigênio.

Através da análise realizada, foi comprovada uma redução significativa no consumo de GN pelo aumento do volume de oxigênio injetado no ar de combustão do forno. Assim, o operador pode solicitar um enriquecimento máximo e o sistema limitará o consumo de acordo com a disponibilidade e usar o máximo permitido de oxigênio automaticamente.

Portanto, com a implantação deste controlador antecipatório o uso do oxigênio foi otimizado, reduzindo assim os custos de insumos dos processos, através da redução do consumo de gás natural e utilização de aproximadamente toda quantidade de oxigênio contratada pela empresa sem interferências entre os principais consumidores, além de evitar ocorrências de distúrbios nos controladores do Forno WB2 e aumento da segurança operacional do sistema e dos envolvidos no processo produtivo.

\footnotetext{
* Contribuição técnica ao $18^{\circ}$ Seminário de Automação e TI Industrial, 23 a 26 de setembro de 2014,
} São Paulo, SP, Brasil. 


\section{Agradecimentos}

Os autores agradecem a todos envolvidos no projeto de enriquecimento do ar de combustão do forno WB2, ao Sr. Jadir Assis Barros do departamento de Engenharia de Implantação, aos Srs. Luciano Lellis Miranda, Bejamin Fullin Junior, Isac Quintao Pessoa do departamento de Eficiência Energética e Reginaldo Frinhani Carlos do departamento de Utilidades, aos Srs. Tiago Martins de Oliveira Egídio e Henrique de Castro Rodrigues do Controle de Processo da LTQ, aos Srs. Evandro Soares Bernardes, José Gomes dos Santos e Fernando Dias Arthuso do setor de Automação e Instrumentação da Aperam, e aos representantes da empresa $L$ \& $M$, que de forma direta e indireta contribuíram para o sucesso de toda implantação deste sistema.

\section{REFERÊNCIAS}

1 Seborg DE, Edgar TF. Mellichamp DA. 1989. Process Dynamics and Control, John Wiley \& Sons, NY.

* Contribuição técnica ao $18^{\circ}$ Seminário de Automação e TI Industrial, 23 a 26 de setembro de 2014, São Paulo, SP, Brasil. 